\title{
Serological evidence for Saint Louis encephalitis virus in free-ranging New World monkeys and horses within the upper Paraná River basin region, Southern Brazil
}

\author{
Walfrido Kühl Svoboda ${ }^{[1]}$, Lívia Carício Martins ${ }^{[2]}$, Luciano de Souza Malanski ${ }^{[3]}$, \\ Marcos Massaaki Shiozawa ${ }^{[4]}$, Kledir Anderson Hofstaetter Spohr ${ }^{[5]}$, \\ Carmen Lúcia Scortecci Hilst ${ }^{[6]}$, Lucas M. Aguiar ${ }^{[7]}$, Gabriela Ludwig ${ }^{[8]}$, \\ Fernando de Camargo Passos ${ }^{[9]}$, Lineu Roberto da Silva ${ }^{[10]}$, Selwyn Arlington Headley ${ }^{[11]}$ \\ and Italmar Teodorico Navarro[11]
}

[1]. Universidade Federal da Integração Latino-Americana (UNILA), Instituto Latino-Americano de Ciências da Vida e da Natureza (ILACVN), Foz do Iguaçu, PR, Brasil [2]. Departamento de Arbovirologia e Febres Hemorrágicas, Instituto Evandro Chagas, Ananindeua, PA. [3]. Instituto Chico Mendes de Conservação da Biodiversidade, Porto Velho, RO. [4]. Escola de Medicina Veterinária, Universidade Norte do Paraná, Arapongas, PR. [5]. Escola de Medicina Veterinária, Universidade de Cuiabá, Cuiabá, MT. [6]. Departamento de Clínica Veterinária, Universidade Estadual de Londrina, Londrina, PR. [7]. Universidade Federal da Integração Latino-Americana, Foz do Iguaçu, PR. [8]. Centro Nacional de Pesquisa e Conservação de Primatas Brasileiros, Instituto Chico Mendes de Conservação da Biodiversidade, João Pessoa, PB. [9]. Departamento de Zoologia, Universidade Federal do Paraná, Curitiba, PR. [10]. Secretaria da Saúde do Paraná, Curitiba, PR. [11]. Departamento de Medicina Veterinária Preventiva, Universidade Estadual de Londrina, Londrina, PR.

\begin{abstract}
Introduction: Saint Louis encephalitis virus (SLEV) primarily occurs in the Americas and produces disease predominantly in humans. This study investigated the serological presence of SLEV in nonhuman primates and horses from southern Brazil. Methods: From June 2004 to December 2005, sera from 133 monkeys (Alouatta caraya, n=43; Sapajus nigritus, n=64; Sapajus cay, $\mathrm{n}=26$ ) trap-captured at the Paraná River basin region and 23 blood samples from farm horses were obtained and used for the serological detection of a panel of 19 arboviruses. All samples were analyzed in a hemagglutination inhibition (HI) assay; positive monkey samples were confirmed in a mouse neutralization test (MNT). Additionally, all blood samples were inoculated into C6/36 cell culture for viral isolation. Results: Positive seroreactivity was only observed for SLEV. A prevalence of SLEV antibodies in sera was detected in Alouatta caraya (11.6\%; 5/43), Sapajus nigritus $(12.5 \%$; 8/64), and S. cay (30.8\%; $8 / 26$ ) monkeys with the HI assay. Of the monkeys, $2.3 \%$ (1/42) of A. caraya, 6.3\% 94/64) of S. nigritus, and $15.4 \%(4 / 26)$ of S. cay were positive for SLEV in the MNT. Additionally, SLEV antibodies were detected by HI in 39.1\% (9/23) of the horses evaluated in this study. Arboviruses were not isolated from any blood sample. Conclusions: These results confirmed the presence of SLEV in nonhuman primates and horses from southern Brazil. These findings most likely represent the first detection of this virus in nonhuman primates beyond the Amazon region. The detection of SLEV in animals within a geographical region distant from the Amazon basin suggests that there may be widespread and undiagnosed dissemination of this disease in Brazil.
\end{abstract}

Keywords: Saint Louis encephalitis. Serology. New World monkeys. Horses. Arboviruses.

\section{INTRODUCTION}

Saint Louis encephalitis virus (SLEV) belongs to the genus Flavivirus, family Flaviviridae, which consists of approximately 70 virus species and subspecies distributed worldwide ${ }^{1}$. Most flaviviruses are transmitted between susceptible vertebrates by hematophagous arthropods, in particular mosquitos ${ }^{1,2}$. Flaviviruses are the most import causes of infectious diseases

\footnotetext{
Address to: Dr. Selwyn Arlington Headley. Dept ${ }^{\circ}$ de Medicina Veterinária Preventiva/UEL. Rodovia Celso Garcia Cid, PR 445, km 380, Campus Universitário, Caixa Postal 10.001, 86057-970 Londrina, PR, Brasil.

Phone/Fax: 5543 3371-4485

e-mail: selwyn.headley@uel.br

Received 18 April 2014

Accepted 30 June 2014
}

in humans from Brazil ${ }^{3}$; these viruses include Bussuquara, Cacipacore, dengue (serotypes 1, 2, 3, and 4), Iguape, Ilhéus, Rocio, Saint Louis encephalitis, and yellow fever ${ }^{3,4}$.

SLEV may have initially originated in Central America $^{5}$, but it has now disseminated throughout the Americas, with reports of its presence in the $\mathrm{USA}^{6,7}$, Canada ${ }^{7}$, Argentina ${ }^{8,9}$, Uruguay ${ }^{10}$, and Trinidad ${ }^{11}$. In Brazil, SLEV was likely first isolated in the 1960s from a pool of Sabethes belisarioi mosquitoes captured on the Belém-Brasília Highway ${ }^{12}$. Since then, this virus has been identified predominantly in humans ${ }^{13-15}$ and horses ${ }^{16-18}$ from Brazil.

Serological confirmation of SLEV in wildlife is very rare; it has been described in the white-tailed deer in the USA ${ }^{19}$, while seropositivity has been demonstrated in wild and sentinel animals and arthropods from both the Amazon region ${ }^{20,21}$ and the State of São Paulo ${ }^{22}$, Brazil. Moreover, at least three epizootic incidents of SLEV have occurred in nonhuman primates, 
including sentinel Cebus monkeys in the Brazilian Amazon region $^{21}$. Additionally, a serological survey conducted in French Guiana detected low levels of SLEV antibodies in free-ranging primates $^{23}$.

This study presents the findings of a serological investigation of SLEV in free-ranging New World monkeys and farm horses from southern Brazil.

\section{METHODS}

\section{Study location}

All monkeys used in this study were trap-captured within the Porto Rico County region, located between the northwestern region of the State of Paraná and the southeast region of the State of Mato Grosso do Sul, on the upper Paraná River in Brazil (Figure 1). This region consists of islands and sub-tropical forest reserves (where the animals were captured) that are protected by the Instituto Brasileiro do Meio Ambiente e dos Recursos Naturais Renováveis (IBAMA). The riparian forests of the islands of Mutum, Porto Rico, Gaivota, and Japonesa and the forests on the opposite shore of the Paraná River were included in this study. Porto Rico County is located in the northwestern region of the State of Paraná $\left(22^{\circ} 46^{\prime} 20^{\prime \prime}\right.$ S latitude and 53 $16^{\circ} 01^{\prime \prime}$ W-GR longitude). This sub-tropical region has an average annual rainfall of $1,200-1,300 \mathrm{~mm}$ and temperatures ranging from 16 to $29^{\circ} \mathrm{C}$.

\section{Nonhuman primates}

One hundred thirty-three nonhuman primates [43 Alouatta caraya (black and golden howler monkey), 64 Sapajus nigritus, and 26 S. cay (both called capuchin monkeys)] were trapcaptured as previously described ${ }^{24}$. The biological data for the captured nonhuman primates are given in Table 1; all primates were captured between June 2004 and December 2005 by a team of biologists and veterinarians with permission from IBAMA (license number 104/04). All primates were anesthetized ${ }^{25}$, after which blood samples were obtained by jugular or brachial venipuncture, and sera were centrifuged $( \pm 1,000 \mathrm{~g})$ and stored at $-196^{\circ} \mathrm{C}$ until used. All trapped animals were released after complete recovery at the capture location.

All captured primates were strict forest inhabitants. However, a number of S. nigritus specimens ( $\mathrm{n}=13)$ were trapped in a forest reserve (within the Paraná River basin) close to a farm whose owner reportedly had frequent contact with monkeys.

\section{Horses}

Blood samples were obtained by jugular venipuncture from 23 mixed-breed adult horses (16 males and 7 females) located in proximity to where the $S$. cay monkeys were captured. All sampled horses were located on the same property and were representative of the total horse population maintained at this holding. Serum samples were obtained and stored at $-196^{\circ} \mathrm{C}$ until they were used.

\section{Serological assays}

All serological assays were performed at the Evandro Chagas Institute (IEC-PA), Department of Arbovirology and Hemorrhagic Fevers, Belém, PA, Brazil. All samples were stored on dry ice and then air-shipped to Belém.

\section{Hemagglutination inhibition test}

All samples were initially subjected to a microplate hemagglutination inhibition (HI) test ${ }^{26}$ against a panel of standardized antigens for 19 arboviruses, including four from the genus Alphavirus (eastern equine encephalomyelitis, western equine encephalomyelitis, Mayaro, and Mucambo),
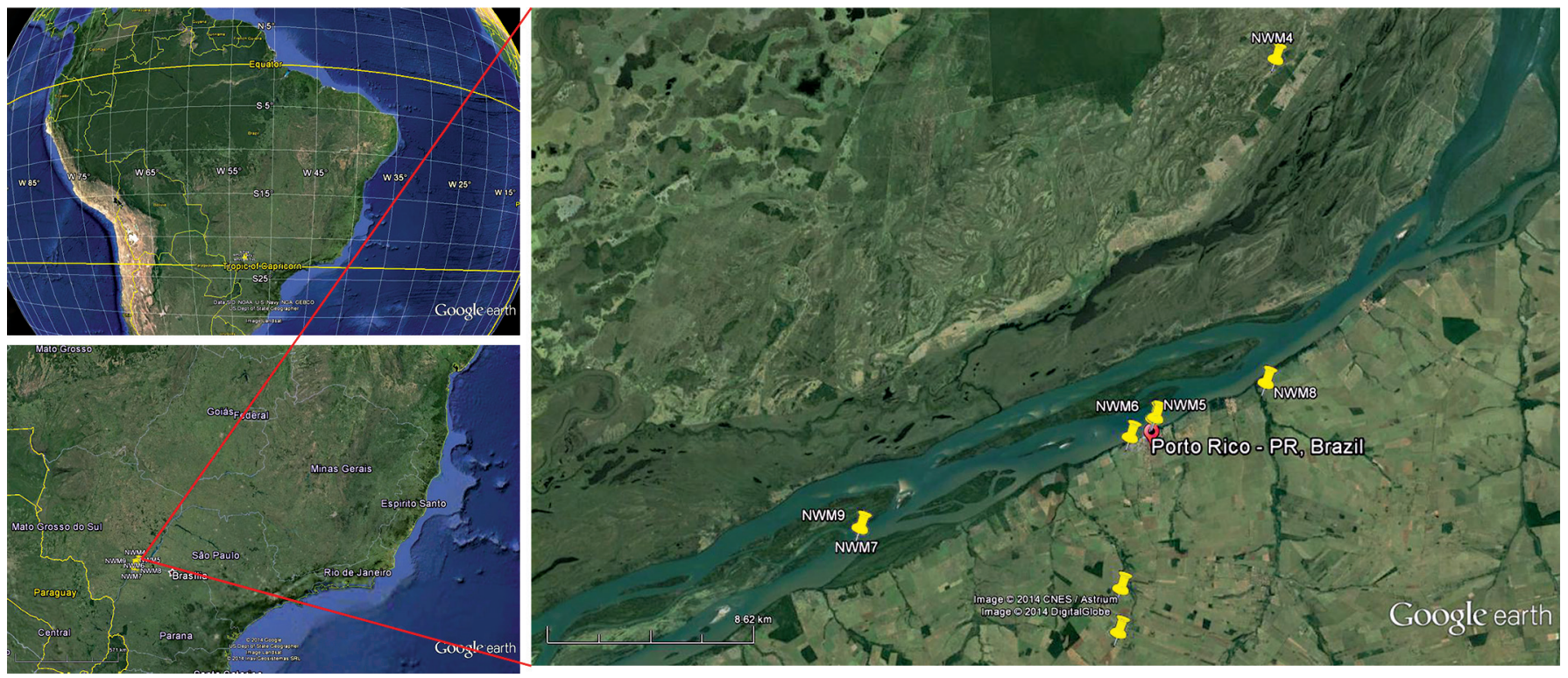

FIGURE 1 - Google earth images illustrating the region where the research was conducted. The yellow pins indicate the coordinates where monkeys seropositive for Saint Louis encephalitis virus were trap-captured. 
TABLE 1 - The species, sex, and age distributions of free-ranging New World monkeys captured within the Porto Rico County region, Southern Brazil.

\begin{tabular}{|c|c|c|c|c|c|c|c|c|c|}
\hline Monkey species & \multicolumn{4}{|c|}{ Female (F) } & \multicolumn{4}{|c|}{ Male (M) } & Total (F, M) \\
\hline Alouatta caraya & 1 & 3 & - & 16 & - & 5 & 6 & 12 & $43(\mathrm{~F}=20, \mathrm{M}=23)$ \\
\hline Sapajus nigritus & - & 4 & 2 & 13 & 5 & 16 & 3 & 21 & $64(\mathrm{~F}=19, \mathrm{M}=45)$ \\
\hline Sapajus cay & - & 5 & 2 & 4 & 1 & 2 & 2 & 10 & $26(\mathrm{~F}=11, \mathrm{M}=15)$ \\
\hline
\end{tabular}

six Flavivirus (yellow fever, Saint Louis encephalitis, Rocio, Ilhéus, Cacipacoré and Bussuquara), eight Orthobunyavirus (Oropouche, Caraparu, Catú, Guaroa, Maguari, Tacaiuma, Utinga and Belém) and one from the genus Phlebovirus (Icoaraci). Animals were considered seropositive when a titer of $\geq 20$ was observed with the HI assay.

\section{Mouse neutralization test}

All positive monkey sera with HI titers $>20$ were subjected to a mouse neutralization test (MNT), a confirmatory assay that was used to characterize the virus associated with the infection and performed according to a previously described protocol ${ }^{26}$. The results were calculated using the neutralization logarithmic index $(\mathrm{NLI})^{27}$. Sera from horses were not evaluated by MNT.

\section{Virus isolation}

All blood samples were inoculated into Aedes albopictus cell culture (clone C6/36); immunofluorescence was used for viral identification ${ }^{28}$.

\section{Statistical analysis}

Statistical significance was analyzed using the Chi-square test (Yates corrected) to establish differences between the characteristics evaluated (species, gender, age, and the presence of horses). Associations between variables and positivity were determined by odds ratios (ORs) with $95 \%$ confidence levels. The results were considered statistically significant when the $\rho$-value was $5 \%$.

\section{Ethical considerations}

This study was approved by the Animal Experimental Ethics Committee, Universidade Estadual de Londrina (Protocol number 34/05).

\section{RESULTS}

\section{Serological assay and virus isolation from nonhuman primates}

According to the HI assay, SLEV antibodies were present in primates, specifically in $11.6 \%(5 / 43)$ of $A$. caraya, $12.5 \%(8 / 64)$ of $S$. nigritus, and $30.8 \%(8 / 26)$ of $S$. cay animals (Table 2). However, confirmation of SLEV infection by MNT was obtained for only $2.3 \%$ (1/43) of $A$. caraya, $6.3 \%$ (4/64) of $S$. nigritus and $15.4 \%(4 / 26)$ of $S$. cay primates (Table 2). Arboviruses were not isolated from any of the 133 primate-derived

TABLE 2 - Results of hemagglutination inhibition assays and mouse neutralization tests for free-ranging New World monkeys captured within the Porto Rico County region, Southern Brazil.

\begin{tabular}{|c|c|c|c|c|c|c|c|}
\hline HI result*(antibody titer) & \multicolumn{2}{|c|}{ Alouatta caraya } & \multicolumn{2}{|c|}{ Sapajus nigritus } & \multicolumn{2}{|c|}{ Sapajus cay } & $\begin{array}{c}\text { Total } \\
\text { (male/female) }\end{array}$ \\
\hline Negative & 21 & 17 & 40 & 16 & 10 & 8 & $112(71 / 41)$ \\
\hline 20 & - & 2 & 2 & 1 & 2 & 2 & $9(4 / 5)$ \\
\hline 40 & 2 & $1^{(2.7)}$ & 1 & - & $2^{(1.8 / 2.7)}$ & - & $6(5 / 1)$ \\
\hline 160 & - & - & - & $1^{(2.8)}$ & - & - & $1(-/ 1)$ \\
\hline 320 & - & - & - & - & - & - & - \\
\hline 640 & - & - & $1^{(3.5)}$ & - & $1^{(3.1)}$ & - & $2(2 /-)$ \\
\hline Total & 23 & 20 & 45 & 19 & 15 & 11 & $133(83 / 50)$ \\
\hline
\end{tabular}

HI: hemagglutination inhibition. ${ }^{*} \mathrm{HI}$ test results: positive $\mathrm{HI} \geq 20$; ${ }^{(n)}$ neutralization logarithmic index (NLI): positive NLI $\geq 1.8$. 


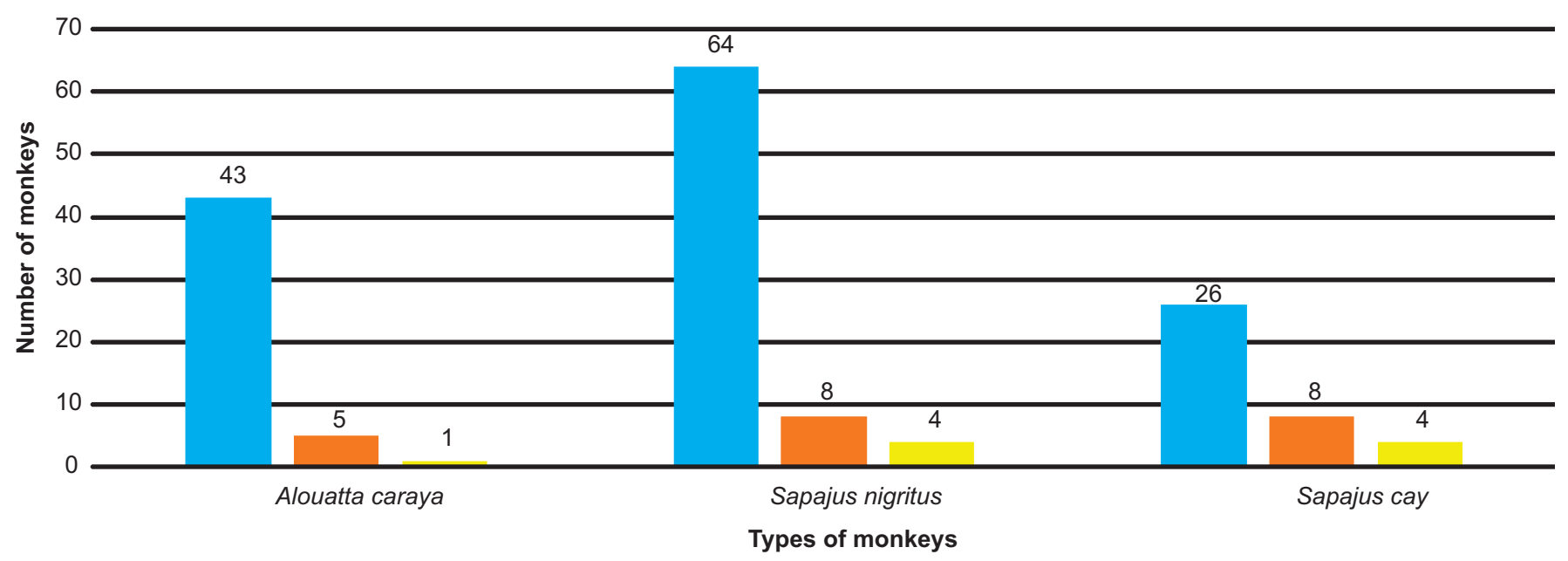

Total captured monkeys (by species)

Saint Louis encephalitis virus positive monkeys $(\mathrm{HI})$

Saint Louis encephalitis virus positive monkeys (MNT)

FIGURE 2 - Relationships between the total numbers of captured monkeys (by species) and positive results in the hemagglutination inhibition (HI) and mouse neutralization test (MNT) assays.

blood samples, although SLEV antibodies were detected by HI in $15.8 \%(21 / 133)$ of serum samples, with HI titers to SLEV ranging from 20 to 640 (Table 2 and Figure 2). Negative seroreactivity was observed for all other arboviruses.

The association of the results obtained based on NMT analysis of characteristics evaluated (species, sex, age, and the presence of horses within the same habitat) with the neutralization logarithm index (NLI) is summarized in Table 3. The prevalence of anti-SLEV antibodies was elevated in S. cay $(15.4 \% ; 4 / 26)$ relative to $S$. nigritus $(6.3 \% ; 4 / 64)$ and $A$. caraya $(2.3 \% ; 1 / 43)$ primates. Interestingly, negative seroreactivity of HI to SLEV antibodies was observed in infant and juvenile primates, while SLEV antibody serum prevalence was identified in sub-adult $(13.3 \% ; 2 / 15)$ and adult $(9.2 \%$; $7 / 76)$ animals, most likely due to their more extensive contact with this pathogen. Additionally, primates that live within proximity to farm horses demonstrated elevated seroreactivity to SLEV antibodies $(15.4 \%$; $4 / 26)$ compared to those living without potential contact with horses $(4.8 \% ; 5 / 107)$. However, no significant differences were observed based on species $(\rho=0.1090)$, sex $(\rho=0.7281)$, age $(\rho=0.1876)$, and the presence of horses within the same habitat $(\rho=0.0727)$.

\section{Serological assay and virus isolation from horses}

The overall seroprevalence of SLEV antibodies in horses was $39.1 \%(9 / 23)$ and was elevated in females $(57.1 \% ; 4 / 7)$ relative to male horses $(31.3 \% ; 5 / 16)$. SLEV antibody titers in seropositive horses were as follows: 160 (three males; two females), 320 (one male and female) and 640 (one male and female). However, significant differences were not observed based on sex $[\rho=0.3630$; OR $=0.34(0.04<\mathrm{OR}<2.91)]$, and these results were not confirmed with the MNT assay. Additionally, arboviruses were not isolated from any of the
23 horse-derived blood samples, but as previously observed in primates, specific seropositivity only to SLEV antibodies was observed with the HI assay.

\section{DISCUSSION}

The results of this study reveal that we have identified the presence of SLEV in several species of nonhuman primates and horses from southern Brazil. The classical HI and MNT methodologies used during this investigation are based on the conventional serologic diagnosis of flavivirus due to the presence of virus-specific antibodies in the serum. Similar serological strategies have been used to detect SLEV in primates $^{23}$, white-tailed deer ${ }^{19,29}$, livestock ${ }^{11}$, mules ${ }^{19}$, and horses $^{8,10,11,17,18}$. The importance of these results lies primarily in the observation of SLEV circulation in a completely new habitat within Brazil, considering that most cases of SLEV have been described within the Amazon region ${ }^{4,20-22}$. However, SLEV was recently isolated from a horse in the State of Minas Gerais ${ }^{16}$, and SLEV has been serologically identified in both horses from Corumba, Central West Brazil ${ }^{17}$ and in patients from the State of São Paulo ${ }^{14}$. These results suggest a southern drift of SLEV from the Amazon region to other parts of continental Brazil, most likely attributable to migratory birds ${ }^{16,21,22}$.

In the USA, SLEV causes encephalitis in approximately 100 human cases annually ${ }^{30}$ and is one of the most common causes of arbovirus-induced disease ${ }^{31}$, with sporadic epidemics ${ }^{6,30,31}$. However, this arboviral disease has different epidemiological features in Brazil, largely in terms of the relatively few cases of SLEV-induced encephalitis identified in humans ${ }^{20,22}$. Additionally, most flaviviruses that occur in Brazil, with the exception of dengue virus, are predominantly maintained 
TABLE 3 - Associations between the characteristics studied (species, sex, age, and the presence of horses within the same habitat) and the presence of anti-Saint Louis encephalitis virus antibodies (neutralization logarithm index) in serum samples of free-ranging New World Monkeys.

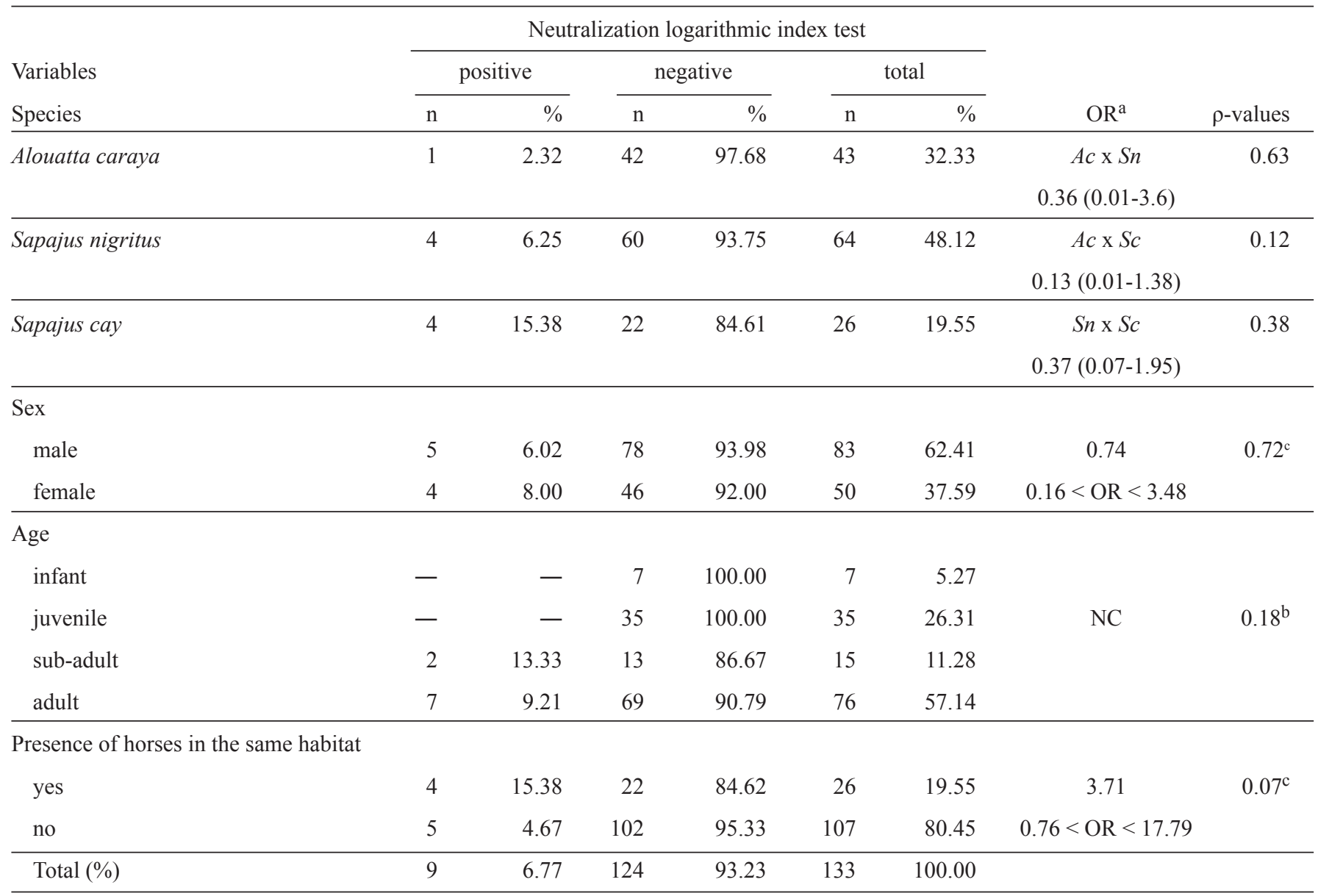

Ac: Alouatta caraya; $\mathbf{S n}$ : Sapajus nigritus; $\mathbf{S c}$ : Sapajus cay; NC: not calculated; $\mathbf{O R}^{\mathbf{a}}$ : odds ratio (inferior and superior limits); ${ }^{\mathbf{b}}$ chi-square; 'Fisher's exact test.

as sylvatic zoonotic diseases that occasionally produce infections in humans and domestic animals that have entered the ecosystems where these viruses occur ${ }^{4}$. Consequently, it can be speculated that this epidemiological difference might possibly be attributable to specific environmental and biological conditions within Brazil that alter the virulence or pathogenicity of SLEV in humans. Although the factors that are actively or otherwise associated with this phenomenon have not been fully elucidated, at least two theories should be considered. First, the elevated endemicity of other closely related flaviviruses that elicit cross-protection in humans, such as that occurring with dengue and yellow fever immunization, might easily result in the underdiagnosis of SLEV; this occurred in a study of 519 patients who were initially diagnosed as having dengue fever, but later molecular investigation confirmed the presence of SLEV in eight of them ${ }^{14}$. Secondly, the difficulty in efficiently recognizing and/or diagnosing SLEV encephalitis in patients at both public and private health services might also contribute to the reduced number of cases in Brazil, considering that patients may either be asymptomatic ${ }^{4,16}$ or present with flu-like disease syndromes that can progress to acute or subacute meningeal and focal neurological manifestations ${ }^{32}$. Moreover, three patients from an outbreak of SLEV in northwestern São Paulo demonstrated hemorrhagic manifestations typical of dengue fever virus ${ }^{33}$. Taken together, the confirmation of SLEV in several states in Brazil ${ }^{13,14,16}$ in addition to the Amazon region may suggest dissemination due to migratory birds ${ }^{16,22}$, as previously postulated. Furthermore, Culex declarator and Culex coronator are known vectors, while monkeys, sloths, armadillos, and marsupials are reservoirs of this virus in Brazil ${ }^{4}$. Therefore, the seropositivity of nonhuman primates and horses to SLEV demonstrated in this study in a region geographically distant from the Amazon region is of great concern, and additional investigation must be conducted to understand the dynamics associated with this virus in a new environment but in conventional hosts.

During this investigation, the majority $(57.1 \% ; 12 / 21)$ of seropositive monkeys demonstrated titers of SLEV according to $\mathrm{HI}$ that were $\geq 40$, suggesting that these antibodies are attributable to the presence of SLEV and not cross-reactivity 
from contact with similar related viruses. Alternatively, in a seroepidemiological survey conducted in French Guiana, primates had low antibody titers to SLEV $(\mathrm{HI}<40)$ but elevated titers to yellow fever $(\mathrm{HI}>320)$, and the authors suggested that that SLEV antibodies identified could have been due to crossreactions with yellow fever virus ${ }^{23}$. Low titers of SLEV were also identified in horses, livestock, and wildlife from the island of Trinidad ${ }^{11}$. However, during this investigation, seropositivity was only identified for SLEV, and negative results were obtained with all other viruses by HI, indicating that there was no crossreaction with any similarly related virus.

In Argentina, SLEV studies have focused primarily on populations of mosquitoes ${ }^{34,35}$, humans ${ }^{36}$, and horses ${ }^{8}$, but the importance of monkeys in the sylvatic SLEV cycle has not been investigated. However, during this study, serological results confirmed the participation of nonhuman primates in the maintenance cycle of SLEV in southern Brazil. Consequently, these results most likely represent the first identification of SLEV in nonhuman primates beyond the Amazon region of Brazil.

Horses are commonly found in the region where sample collection was performed, largely on farms that are close to forested areas, and the relationships contributing to the presence of SLEV antibodies in these animals should be considered. Elevated prevalence rates of SLEV antibodies in horses from the Amazon ${ }^{18}$ and Pantanal ${ }^{17,18}$ regions have been described, but this report is the first description of SLEV in southern Brazil within an ecosystem that is very distant and quite different from the Amazon and Pantanal regions. Therefore, these results suggest that horses may participate as vertebrate hosts in the dissemination of SLEV and most likely should be considered amplifying sources of SLEV for primates, or vice versa. However, additional investigations must be performed to confirm this theory.

This report is the first describing the seroprevalence of specific SLEV antibodies in free-ranging monkeys within the State of Paraná, southern Brazil, and implicates nonhuman primates in the natural maintenance cycle of SLEV in the Southern Cone region, where an SLEV encephalitis outbreak was identified in northern Argentina ${ }^{35}$. Future research will aim to identify local mosquito and human populations to establish their roles in the SLEV life cycle.

\section{ACKNOWLEDGMENTS}

We are grateful to Mr. Basílio S. Buna, Geraldo M. da Silva, and Luiz R.O. Costa of the Evandro Chagas Institute (IEC-PA), Department of Arbovirology and Hemorrhagic Fevers, for performing all serological assays. Our gratitude is also extended to the Entomology Team of SESA-PR (Porto Rico-PR) for technical support during sample collection and to the Instituto Brasileiro do Meio Ambiente e dos Recursos Naturais Renováveis (IBAMA) for permission to capture primates for this experiment. We are also grateful to Dr. João Luis Garcia, Universidade Estadual de Londrina, for assistance with the statistical analysis.

\section{CONFLICT OF INTEREST}

The authors declare that there is no conflict of interest.

\section{FINANCIAL SUPPORT}

Secretaria Estadual de Saúde do Paraná (SESA-PR), Secretaria de Estado da Ciência, Tecnologia e Ensino Superior (SETI-PR), Coordenação de Aperfeiçoamento de Pessoal de Nivel Superior (CAPES), and Conselho Nacional de Desenvolvimento Científico e Tecnológico (CNPq). Gabriela Ludwig has a temporary scholarship from Centro Nacional de Pesquisa e Conservação de Primatas Brasileiros, Instituto Chico Mendes de Conservação da Biodiversidade, Projeto Nacional de Ações Integradas Público-Privadas para Biodiversidade - Fundação de Empreendimentos Pesquisa e Desenvolvimento.

\section{REFERENCES}

1. International Committee on Taxonomy of Viruses (ICTV). Virus Taxonomy, $8^{\text {th }}$ Report of the ICTV. London: Elsevier/Academic Press; 2005.

2. Turell MJ, O'Guinn M, Oliver J. Potential for New York mosquitoes to transmit West Nile virus. Am J Trop Med Hyg 2000; 62:413-414.

3. Batista WC, Kashima S, Marques AC, Figueiredo LTM. Phylogenetic analysis of Brazilian Flavivirus using nucleotide sequences of parts of NS5 gene and 3' non-coding regions. Virus Res 2001; 75:35-42.

4. Figueiredo LTM. The Brazilian flaviviruses. Microbes Infect 2000; 2:1643-1649.

5. Kopp A, Gillespie TR, Hobelsberger D, Estrada A, Harper JM, Miller RA, et al. Provenance and geographic spread of St. Louis encephalitis virus. mBio 2013; 4:e00322-13.

6. Monath TP, Tsai TF. St. Louis Encephalitis: lessons from the last ecade. Am J Trop Med Hyg 1987; 37:S40-S59.

7. Calisher $\mathrm{CH}$. Medically important arboviruses of the United States and Canada. Clin Microbiol Rev 1994; 7:89-116.

8. Tauro L, Marino B, Diaz LA, Lucca E, Gallozo D, Spinsanti L, et al. Serological detection of St. Louis encephalitis virus and West Nile virus in equines from Santa Fe, Argentina. Mem Inst Oswaldo Cruz 2012; 107:553-556.

9. Valinotto LE, Barrero PR, Viegas M, Alvarez Lopez MC, Mistchenko AS. Molecular evidence of St. Louis encephalitis virus infection in patients in Buenos Aires, Argentina. J Clin Virol 2012; 54:349-351.

10. Burgueno A, Spinsanti L, Diaz LA, Rivarola ME, Arbiza J, Contigiani M, et al. Seroprevalence of St. Louis encephalitis virus and West Nile virus (flavivirus, flaviviridae) in horses, Uruguay. BioMed Res Int 2013; 2013. doi: 10.1155/2013/582957.

11. Thompson NN, Auguste AJ, Coombs D, Blitvich BJ, Carrington CV, Rosa AP, et al. Serological evidence of flaviviruses and alphaviruses in livestock and wildlife in Trinidad. Vector Borne Zoonotic Dis 2012; 12:969-978.

12. Theiler M, Downs WG. The arthropod-borne viruses of vertebrates. An account of the Rockefeller Foundation virus program, 1951-1970. $1^{\text {st }}$ ed. New Haven: Yale University Press; 1973.

13. Rocco IM, Santos CL, Bisordi I, Petrella SM, Pereira LE, Souza RP, et al. St. Louis encephalitis virus: first isolation from a human in Sao Paulo State, Brazil. Rev Inst Med Trop Sao Paulo 2005; 47:281-285.

14. Terzian AC, Mondini A, Bronzoni RV, Drumond BP, Ferro BP, Cabrera EM, et al. Detection of Saint Louis encephalitis virus in Dengue-suspected 
cases during a dengue 3 outbreak. Vector Borne Zoonotic Dis 2011; 11:291-300.

15. Mondini A, Bronzoni RV, Cardeal IL, Santos TM, Lazaro E, Nunes SH, et al. Simultaneous infection by DENV-3 and SLEV in Brazil. J Clin Virol 2007; 40:84-86

16. Rosa R, Costa EA, Marques RE, Oliveira TS, Furtini R, Bomfim MRQ, et al. Isolation of Saint Louis Encephalitis Virus from a horse with neurological disease in Brazil. PLoS Negl Trop Dis 2013; 7:e2537.

17. Pauvolid-Correa A, Tavares FN, Costa EV, Burlandy FM, Murta M, Pellegrin AO, et al. Serologic evidence of the recent circulation of Saint Louis encephalitis virus and high prevalence of equine encephalitis viruses in horses in the Nhecolandia sub-region in South Pantanal, Central-West Brazil. Mem Inst Oswaldo Cruz 2010; 105:829-833.

18. Rodrigues SG, Oliva OP, Araujo FAA, Martins LC, Chiang JO, Henriques DF, et al. Epidemiology of Saint Louis encephalitis virus in the Brazilian Amazon region and in the State of Mato Grosso do Sul, Brazil: elevated prevalence of antibodies in horses. Rev Pan-Amazonica Saude 2010; $1: 81-86$.

19. Hoff GL, Issel CJ, Trainer DO, Richards SH. Arbovirus serology in North Dakota mule and white-tailed deer. J Wildl Dis 1973; 9:291-295.

20. Vasconcelos PFC, Travassos da Rosa JFS, Travassos da Rosa APA, Dégallier N, Pinheiro FP, Sá Filho GC. Epidemiology of encephalitis by arboviruses in the Amazon region of Brazil. Rev Inst Med Trop Sao Paulo $1991 ; 33: 465-476$

21. Vasconcelos PFC, Travassos da Rosa APA, Dégallier N, Travassos da Rosa JFS, Pinheiro FP. Clinical and ecoepidemiological situation of human arboviruses in Brazilian Amazonia. Cienc Cult (São Paulo) 1992; 44:117-124.

22. Vasconcelos P, Travassos da Rosa A, Pinheiro F, Shope R, Travassos da Rosa J, Rodrigues S. Arboviruses pathogenic from man in Brazil. In: Travassos da Rosa APA, Vasconcelos PFC, Travassos da Rosa JFS, editors. An overview of arbovirology in Brazil and neighboring countries Belém, PA, Brazil: Instituto Evandro Chagas; 1998. p. 72-99.

23. Thoisy B, Vogel I, Reynes JM, Pouliquen JF, Carme B, Kazanji M, et al. Health evaluation of translocated free-ranging primates in French Guiana. Am J Primatol 2001; 54:1-16.

24. Aguiar LM, Ludwig G, Svoboda WK, Teixeira GM, Hilst CL, Shiozawa MM, et al. Use of traps to capture Black and Gold Howlers (Alouatta caraya) on the Islands of the upper Parana River, southern Brazil. Am J Primatol 2007; 69:241-247.
25. Hilst CLS, Spour KAH, Svoboda WK, Shiozawa MM, Malanski LdS, Aguiar LdM, et al. Estudo e adaptação de protocolo de sedação à base de tiletamina/zolazepan em primatas do gênero Cebu. In: XXVII Congresso Brasileiro da Anclivepa, p. 92. Vitória, Espirito Santo, Brasil; 2006.

26. Shope R, Sather G. Arboviruses. In: Lennette EH, Schmidt NJ, editors. Diagnostic procedures for viral, rickettsial and chlamidial infections. $5^{\text {th }}$ ed. Washington, D.C.: American Public Health Association; 1979. p. $767-814$

27. Reed LJ, Muench H. A simple method of estimating fifty per cent endpoints. Am J Epidemiol 1938; 27:493-497.

28. Beaty BJ, Calisher CH, Shope RE. Arboviruses. In: Schimidt NJ, Emmons EW, editors. Diagnostic procedures for viral, rickettsial and clamydial infeccions. $6^{\text {th }}$ ed. Washington, DC: American Public Health Association; 1989. p. 797-855.

29. Farajollahi A, Gates R, Crans W, Komar N. Serologic evidence of West Nile virus and St. Louis encephalitis virus infections in white-tailed deer (Odocoileus virginianus) from New Jersey, 2001. Vector Borne Zoonotic Dis 2004; 4:379-383.

30. Center for Disease Control and Prevention (CDC). Saint Louis encephalitis. Techincal data. Atlanta, GA: CDC; 2014.

31. Reimann CA, Hayes EB, DiGuiseppi C, Hoffman R, Lehman JA, Lindsey NP, et al. Epidemiology of neuroinvasive arboviral disease in the United States, 1999-2007. Am J Trop Med Hyg 2008; 79:974-979.

32. Gould EA, Solomon T. Pathogenic flaviviruses. Lancet 2008; 371: 500-509.

33. Mondini A, Cardeal IL, Lazaro E, Nunes SH, Moreira CC, Rahal P, et al. Saint Louis encephalitis virus, Brazil. Emerg Infect Dis 2007; 13: 176-178.

34. Diaz LA, Flores FS, Beranek M, Rivarola ME, Almirón WR, Contigiani MS Transmission of endemic St Louis encephalitis virus strains by local Culex quinquefasciatus populations in Córdoba, Argentina. Trans R Soc Trop Med Hyg 2013; 107:332-334.

35. Diaz LA, Re V, Almiron WR, Farias A, Vazquez A, Sanchez-Seco MP, et al. Genotype III Saint Louis encephalitis virus outbreak, Argentina, 2005. Emerg Infect Dis 2006; 12:1752-1754.

36. Spinsanti LI, Re VE, Diaz MP, Contigiani MS. Age-related seroprevalence study for St. Louis encephalitis in a population from Cordoba, Argentina. Rev Inst Med Trop Sao Paulo 2002; 44:59-62. 